Gut and Liver, Vol. 11, No. 4, July 2017, pp. 504-511

\title{
Pantoprazole Does Not Reduce the Antiplatelet Effect of Clopidogrel: A Randomized Controlled Trial in Korea
}

Yoon Jin Choi ${ }^{1}$, Nayoung $\mathrm{Kim}^{1,2}$, In-Jin Jang ${ }^{3}$, Joo-Youn $\mathrm{Cho}^{3}$, Ryoung Hee Nam ${ }^{1}$, Ji Hyun Park ${ }^{2}$, Hyun Jin Jo ${ }^{1}$, Hyuk Yoon ${ }^{1}$, Cheol Min Shin ${ }^{1}$, Young Soo Park ${ }^{1}$, Dong Ho Lee ${ }^{1,2}$, and Hyun Chae Jung ${ }^{2}$

${ }^{1}$ Department of Internal Medicine, Seoul National University Bundang Hospital, Seongnam, ${ }^{2}$ Department of Internal Medicine and Liver Research Institute, Seoul National University College of Medicine, and ${ }^{3}$ Department of Clinical Pharmacology and Therapeutics, Seoul National University Hospital, Seoul National University College of Medicine, Seoul, Korea

Background/Aims: Concerns that proton pump inhibitors (PPIs) diminish the efficacy of clopidogrel could hamper the appropriate prescription of PPIs. We evaluated the influence of pantoprazole on the antiplatelet effect of clopidogrel compared with ranitidine, which is regarded as safe, after stratification of the population according to the presence of a cytochrome (CYP) 2 C19 polymorphism in Korea. Methods: Forty patients who underwent dual antiplatelet therapy were randomized to receive pantoprazole $(n=20)$ or ranitidine $(n=20)$. Platelet aggregation was evaluated by impedance aggregometry at baseline (D0) and 8 days after acid-lowering treatments (D9). CYP2C19 was genotyped by polymerase chain reaction-restriction fragment length polymorphism. Results: After co-treatment, the percentage of clopidogrel low-response was $11.1 \%(2 / 18)$ in the pantoprazole group and $10.5 \%(2 / 19)$ in the ranitidine group $(p=0.954)$. The impedance values with adenosine diphosphate stimulus after acid-lowering treatments did not significantly differ between the two groups. In a multiple regression analysis, only ST-elevation myocardial infarction was marginally associated with a reduced antiplatelet effect (odds ratio, 12.07; 95\% confidence interval, 0.84 to 173.78). However, pantoprazole use did not affect the antiplatelet effect after correction for the CYP2C19 polymorphism. Conclusions: This study showed that pantoprazole does not increase platelet aggregation in patients receiving dual antiplatelet therapy (ClinicalTrials.gov number: NCT02733640). (Gut Liver 2017;11:504-511)

Key Words: Clopidogrel low response; Drug interactions; Polymorphism; Proton pump inhibitors

\section{INTRODUCTION}

Dual antiplatelet therapy with aspirin and clopidogrel is generally prescribed for acute coronary syndromes, but antiplatelet agents are associated with gastrointestinal (GI) bleeding. ${ }^{1,2}$ Lowdose aspirin has been associated with a 2-fold greater risk of major GI bleeding compared with placebo., Major GI bleeding increased from $0.7 \%$ in patients on aspirin alone to $1.3 \%$ in those with aspirin and clopidogrel co-therapy during the 12 months. ${ }^{5}$ In addition, the occurrence of upper GI bleeding including minor events associated with the aspirin and clopidogrel co-therapy was reported to be $4.0 \%{ }^{6}{ }^{6}$

Proton pump inhibitors (PPIs) are frequently used along with clopidogrel to reduce the risk of GI bleeding. ${ }^{2,7}$ Since both clopidogrel and some PPIs are prodrugs that use the cytochrome P450 enzyme system, in particular P450 2C19 (CYP2C19), ${ }^{8,9}$ this may cause a competition between them leading to the ineffective platelet inhibition in response to clopidogrel.

Although several studies have raised concerns that PPIs, particularly omeprazole, might abate the antiplatelet effects, ${ }^{10}$ pantoprazole has been regarded as a relratively safe drug regarding the interaction with clopidogrel. ${ }^{11}$ However, there is a scarce study which evaluates whether pantoprazole reduces in clopidogrel's active metabolite levels, especially in Korea, which reflects the difference of research topics between the East and the West due to the interests of journals as well as of the researchers. ${ }^{12}$ Lacking of evidence regarding pantoprazole's minor effect on the pharmacological activity of clopidogrel and a notice of caution from U.S. Food and Drug Administration (FDA) concerning co-administration of the two drugs ${ }^{13}$ still may impede appropriate prescription of PPIs.

With the importance of potential drug-drug interactions, we

Correspondence to: Nayoung Kim

Department of Internal Medicine, Seoul National University Bundang Hospital, 82 Gumi-ro 173beon-gil, Bundang-gu, Seongnam 13620, Korea

Tel: +82-31-787-7008, Fax: +82-31-787-4051, E-mail: nayoungkim49@empas.com

Received on July 16, 2016. Revised on September 16, 2016. Accepted on November 7, 2016. Published online April 11, 2017

pISSN 1976-2283 eISSN 2005-1212 https://doi.org/10.5009/gnl16352

@ This is an Open Access article distributed under the terms of the Creative Commons Attribution Non-Commercial License (http://creativecommons.org/licenses/by-nc/4.0) which permits unrestricted non-commercial use, distribution, and reproduction in any medium, provided the original work is properly cited. 
investigated the influence of concomitant administration of pantoprazole on the antiplatelet effectiveness of clopidogrel by comparison with ranitidine as a control drug according to CYP2C19 genotype and the concentration of clopidogrel and its active metabolite.

\section{MATERIALS AND METHODS}

\section{Study population and randomization}

Between October 2012 and May 2015, patients being treated with a maintenance dose of $75 \mathrm{mg}$ clopidogrel and $100 \mathrm{mg}$ aspirin every day after previous percutaneous coronary intervention $(\mathrm{PCI})$ with coronary stenting were included in the study. Participants received conventional therapy with a loading dose of $600 \mathrm{mg}$ of clopidogrel hydrogen sulfate and $400 \mathrm{mg}$ aspirin. Patients with current GI disorders, a systemic infection, severe liver disorders, congestive heart failure, or a known bleeding tendency including users on bivalirudin or glycoprotein IIb/ III antagonists within the last seven days were excluded from the study. All participants had a normal range of platelet count $(150,000 / \mathrm{mL}$ to $450,000 / \mathrm{mL})$. Patients were randomly assigned to either the pantoprazole $40 \mathrm{mg}$ once-daily group or the ranitidine $150 \mathrm{mg}$ twice-daily group using a computer-generated randomized table. An independent researcher generated the random allocation sequence. Blood samples were collected at 9:00 on day prior to treatment (day 0) and on day 9:00. Measuring impedance was performed by one independent researcher (R.H.N.) in a blinded manner. The study protocol was approved by the Ethics Committee of Seoul National University Bundang Hospital in accordance with the Declaration of Helsinki as revised in Brazil 2013 (IRB number: B-1112/141-006). This trial was registered at ClinicalTrials.gov, NCT02733640. All study participants were willing to sign a consent form before the study begins.

\section{Outcome measurements}

As previously described, ${ }^{14,15}$ impedance aggregometry and outcomes in the form of platelet aggregation in whole blood samples were examined by an impedance aggregometer (Model 590; Chrono-Log Corp., Havertown, PA, USA) and analyzed by the AggroLink software package (Chrono-Log Corp.). Blood samples were collected for platelet aggregation 9 days after pantoprazole or ranitidine treatment. Aggregation of platelet was measured in terms with the change in impedance $(\Omega)$ from start to finish after 6 minutes. Based on the previous studies, an impedance $\leq 5 \Omega$ was defined as a normal response to clopidogrel treatment, while an impedance $>5 \Omega$ was defined as clopidogrel low-response (CLR). ${ }^{14,15}$ The outcomes measured by Chrono-Log 590 aggregometer showed reproducibility with a variability of 10\%. All blood parameters, except for impedance aggregometry, were analyzed at the laboratory of Seoul National University Bundang Hospital.

\section{Measurement of plasma pantoprazole and active metabolite of clopidogrel concentrations}

Blood samples $(2 \mathrm{~mL}$ ) for the determination of plasma concentrations of clopidogrel and its active metabolite $(\mathrm{H} 4)^{16}$ were taken at 0 (preadministration) and 8 days after drug administration. The concentrations were determined using a validated liquid chromatography tandem mass spectrometry (Xevo TQ; Waters, Milford, MA, USA) method. The analytes were separated on a Kinetex C8 column $(2.6 \mu \mathrm{m}$ particle size, $2.1 \times 100 \mathrm{~mm}$; Phenomenex, Torrance, CA, USA). The mobile phase consisted of a mixture of $0.1 \%$ formic acid in distilled water and $0.1 \%$ formic acid in acetonitrile. The calibration curves were linear over the range 0.02 to $10 \mathrm{ng} / \mathrm{mL}$ ( $r \geq 0.9997)$ for clopidogrel and 0.1 to $200 \mathrm{ng} / \mathrm{mL}(\mathrm{r} \geq 0.9990)$ for $\mathrm{H} 4$. The intra- and inter-day precision of the quality control (QC) samples for clopidogrel was $<8.89 \%$, and accuracy was within the range $91.2 \%$ to $106.1 \%$ and $92.90 \%$ to $105.00 \%$, respectively. The intra- and inter-day precision of the QC samples for H4 was $<17.33 \%$, and the accuracy was within the range $94.2 \%$ to $100.5 \%$ and $97.1 \%$ to $101.1 \%$, respectively.

\section{Genotyping for CYP2C19}

Peripheral leukocytes were used for the extraction of genomic DNA. Genotyping for the two variant alleles, CYP2C19*2 and CYP2C19*3, was conducted using polymerase chain reactionrestriction fragment length polymorphism. ${ }^{17,18}$ Others than these two alleles were regarded as CYP2C19*1. The CYP2C19 genotypes were classified into the following three groups: homozygous extensive metabolizers (homo EM; *1/*1), heterozygous EM (hetero EM; ${ }^{*} 1 /{ }^{*} 2$ or ${ }^{*} 1 /{ }^{*} 3$ ) and poor metabolizers $\left(\mathrm{PM} ;{ }^{*} 2 /{ }^{*} 2\right.$, $* 3 / * 3$ or $* 2 / 3$ ).

\section{Statistical analysis}

The primary end-point for analysis in this study was the number of participants with CLR. Secondary analysis end-points included clopidogrel impedance value and adverse events. The characteristics of the two groups (pantoprazole vs ranitidine) were compared using Fisher exact test for categorical variables and the t-test for continuous variables. The Wilcoxon signedrank test was used to compare paired values. Potential predictors of CLR status were identified using a multiple logistic regression analysis based on a stepwise model selection method, from which factors with a p-value $>0.20$ were excluded. Independent of this backward elimination method, some clinically important variables remained independent of $\mathrm{p}$-value.

The odds ratios (OR) for the associations between predictors (independent variables) and CLR status are presented with the corresponding two-sided 95\% confidence intervals (CIs) and pvalues. All analyses were carried out using the SPSS software version 21.0 (IBM Corp., Armonk, NY, USA). 


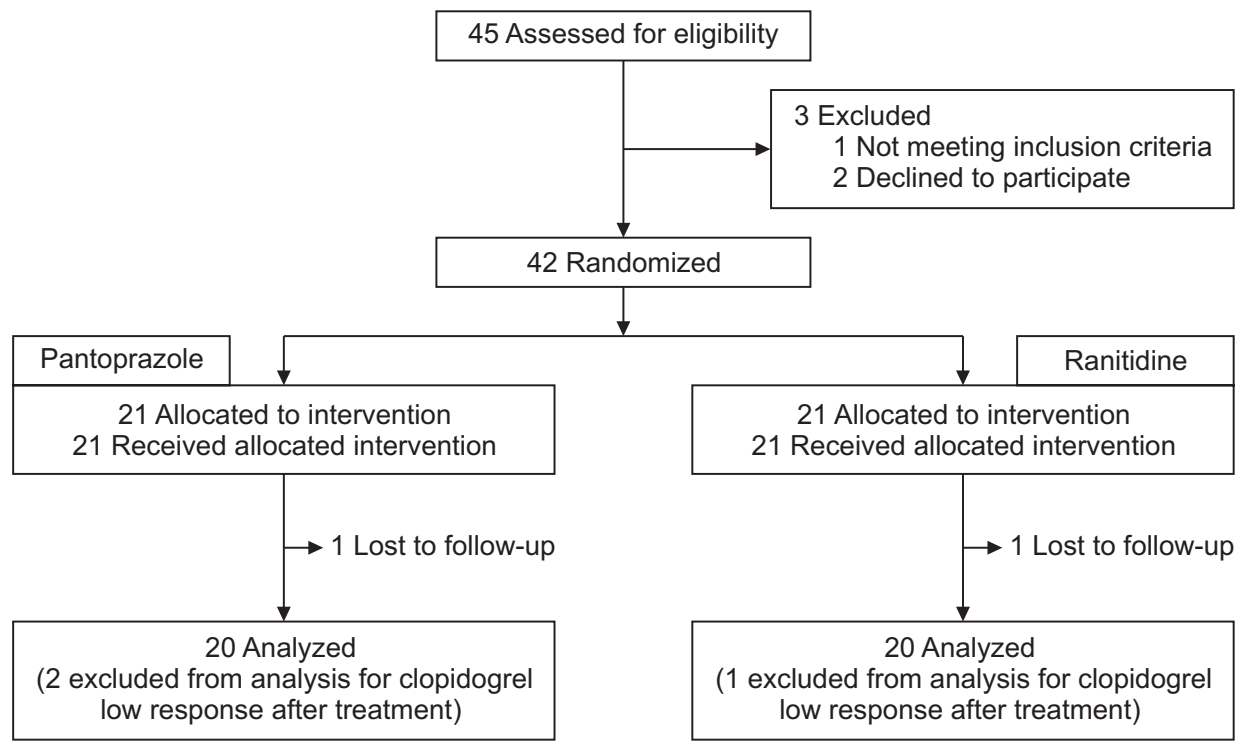

Fig. 1. CONSORT study flow chart.

Table 1. Patient Baseline Characteristics

\begin{tabular}{|c|c|c|c|}
\hline Variable & $\begin{array}{l}\text { Ranitidine } \\
(\mathrm{n}=20)\end{array}$ & $\begin{array}{c}\text { Pantoprazole } \\
(n=20)\end{array}$ & p-value \\
\hline Age, yr & $63.2 \pm 9.7(2.2)$ & $61.2 \pm 10.6(2.4)$ & 0.557 \\
\hline Male sex & $19(95.0)$ & $17(85.0)$ & 0.605 \\
\hline Duration & $296.5 \pm 81.3$ & $206.4 \pm 86.2$ & 0.456 \\
\hline Initial clopidogrel low-response ${ }^{*}$ & 1 & 2 & \\
\hline Clopidogrel low-responder $^{\dagger}$ & 2/19 (10.5) & $2 / 18(11.1)$ & 0.954 \\
\hline Body mass index, $\mathrm{kg} / \mathrm{m}^{2}$ & $25.7 \pm 4.3(1.0)$ & $24.5 \pm 2.6(0.6)$ & 0.308 \\
\hline Hypertension & $14(70.0)$ & $13(65.0)$ & 0.736 \\
\hline Dyslipidemia & $9(45.0)$ & $4(20.0)$ & 0.091 \\
\hline Diabetes mellitus & $10(45.0)$ & $5(25.0)$ & 0.185 \\
\hline Current/ex-smoker & $8(40.0)$ & $7(35.0)$ & 0.744 \\
\hline GFR $<60 \mathrm{~mL} / \mathrm{min}^{\ddagger}$ & $3(15.0)$ & $3(15.0)$ & 0.999 \\
\hline Hematocrit & $42.7 \pm 3.6(0.8)$ & $41.9 \pm 2.5(0.6)$ & 0.411 \\
\hline Platelet count, $10^{3} / \mathrm{mm}^{3}$ & $228.5 \pm 10.8$ & $241.9 \pm 12.6$ & 0.419 \\
\hline \multicolumn{4}{|l|}{ CYP2C19 genotype ${ }^{\S}$} \\
\hline Extensive metabolizer & $9(45.0)$ & $7(35.0)$ & 0.519 \\
\hline Intermediate metabolizer & $10(50.0)$ & $11(55.0)$ & 0.752 \\
\hline Poor metabolizer & $1(5.0)$ & $2(10.0)$ & 0.999 \\
\hline \multicolumn{4}{|l|}{ PCI data } \\
\hline Chronic CAD & $4(20.0)$ & $2(10.0)$ & 0.660 \\
\hline STEMI & $5(25.0)$ & $3(15.0)$ & 0.660 \\
\hline NSTEMI & $4(20.0)$ & $2(10.0)$ & 0.660 \\
\hline UA & $7(35.0)$ & $15(75.0)$ & 0.070 \\
\hline \multicolumn{4}{|l|}{ Medication } \\
\hline$\beta$-Blocker & $11(55.0)$ & $8(40.0)$ & 0.342 \\
\hline ACEI & $16(80.0)$ & $14(70.0)$ & 0.465 \\
\hline Statin & $19(95.0)$ & $16(80.0)$ & 0.342 \\
\hline
\end{tabular}

Data are presented mean \pm SD (standard error), or number (\%).

GFR, glomerular filtration rate; PCI, percutaneous coronary intervention; CAD, coronary artery disease; STEMI, ST-elevation myocardial infarction; NSTEMI, non-STEMI; UA, unstable angina; ACEI, angiotensin-converting-enzyme inhibitor.

${ }^{*}$ At enrollment; ${ }^{\dagger}$ Clopidogrel low-responder was defined as an impedance $>5 \Omega$; ${ }^{\ddagger}$ Estimated GFR by Modification of Diet in Renal Disease formula; ${ }^{8}$ CYP2C19 genotypes were classified into three groups as follows: homozygous extensive metabolizers $\left(* 1 /{ }^{*} 1\right)$, heterozygous extensive metabolizers $\left({ }^{*} 1 /{ }^{*} 2\right.$ or $\left.{ }^{*} 1 /{ }^{*} 3\right)$, and poor metabolizers $\left({ }^{*} 2 /{ }^{*} 2,{ }^{*} 3{ }^{*} 3\right.$ or $\left.{ }^{*} 2 /{ }^{*} 3\right)$. 


\section{RESULTS}

\section{Baseline characteristics}

A total of 42 patients (38 males; mean age, 62.2 years) with previous acute coronary artery disease were finally enrolled in the study (Fig. 1). They were randomly assigned to either pantoprazole or ranitidine group. Excluding two patients who were lost to follow-up, blood samples of 20 patients in each group were collected for platelet aggregation assay. There were no differences in baseline characteristics between the two medication groups (Table 1). No patient experienced major adverse cardiovascular events, defined as myocardial infarction, stent thrombosis, major bleeding, stroke, hospitalization for cardiovascular reasons and death.

\section{Associations between concentrations of clopidogrel and variables}

There were significant associations between the concentrations of clopidogrel and active metabolite (initial: $r=0.617$, $\mathrm{p}=0.001$; follow-up: $r=0.819, \mathrm{p}<0.001$ ). However, the quantity of impedance was significantly associated with neither the concentration of clopidogrel nor that of its active metabolite (initial: $r=0.247, p=0.167$ and $r=0.399, p=0.083$; follow-up: $r=-0.104$, $\mathrm{p}=0.60$ and $\mathrm{r}=-0.302, \mathrm{p}=0.196)$.
In multivariable analyses adjusted for the concentration of clopidogrel and the CYP2C19 genotype, the concentration of active clopidogrel metabolite was associated with that of clopidogrel, but not the CYP2C19 genotype ( $\beta=0.620, p=0.021)$.

\section{Impedance and concentration of active metabolite of clopidogrel}

The initial median aggregometry result for the entire study population when stimulated with $5 \mathrm{mM}$ adenosine diphosphate was $1.00 \Omega$ (interquartile range, 0.25 to 4.00 ). The aggregometry results at baseline and posttreatment were not different between the groups (pantoprazole vs ranitidine) (Table 2). Moreover, there was no significant difference in the impedance values between pre- and posttreatment in each group (Table 2, Fig. 2). Levels of the active metabolite were not significantly changed in both ranitidine and pantoprazole groups (Table 2).

\section{Clopidogrel low-response}

Before the treatment 3/42 patients (7.1\%) were defined as CLR. To evaluate the effect of pantoprazole on platelet aggregation, the three CLR patients and a further two patients who were lost to follow-up were excluded. After treatment, we newly found four (10.8\%) new CLRs (Table 1)-two (11.1\%) in the pantoprazole group, and two (10.5\%) in the ranitidine group $(\mathrm{p}=0.954)$. There was no significant difference.

Table 2. Change in Impedance and Concentration of the Active Clopidogrel Metabolite in Each Acid-Lowering Treatment Group

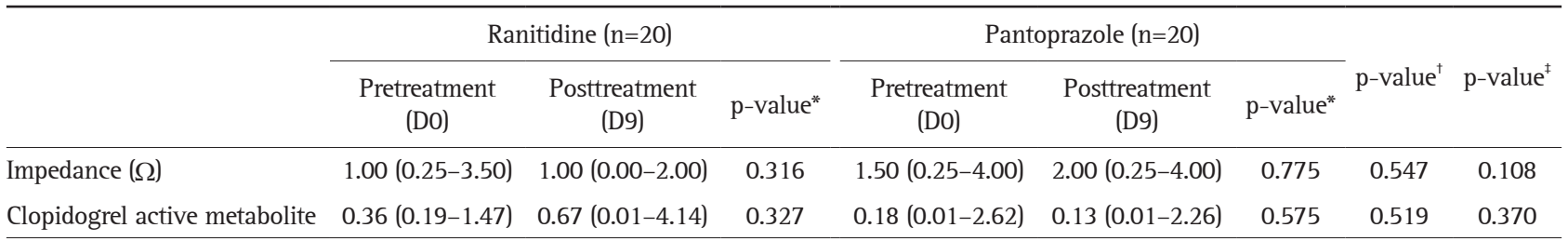

Data are presented as median (interquartile).

${ }^{*}$ Analyses between pretreatment and posttreatment using the Wilcoxon rank-sum test in each group; ${ }^{\dagger}$ Analyses between pretreatment groups using the Mann-Whitney test; ${ }^{\ddagger}$ Analyses between posttreatment groups using the Mann-Whitney test.
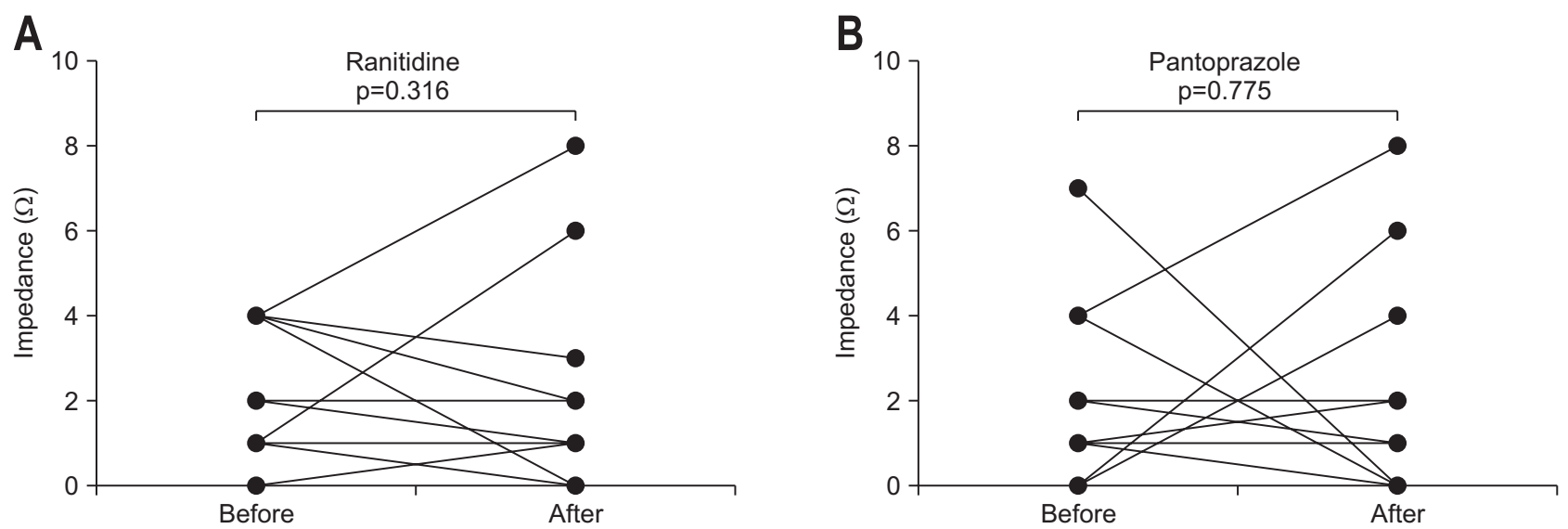

Fig. 2. Antiplatelet effect of clopidogrel on days 0 and 9 in patients with concomitant use of ranitidine (A) and pantoprazole (B) during follow-up. There were no significant differences between the groups (by Wilcoxon signed-rank test). 
The multivariable logistic regression analysis of all 37 patients revealed that only one factor had a strong association with CLR status, STEMI (OR, 263.03; 95\% CI, 1.82 to 38,024.45; $\mathrm{p}=0.028$ ) (Table 3). Among the patients with CLR, three $(75.0 \%$ vs 9.1\%) experienced STEMI. After Firth's correction, the statistical significance was decreased (OR, 12.07; 95\% CI, 0.84 to 173.78; $\mathrm{p}=0.067)$. Although the poor metabolite genotype of CYP2C19 $\left({ }^{*} 2 /{ }^{*} 2,{ }^{*} 3 / * 3\right.$, or $\left.{ }^{*} 2 /{ }^{*} 3\right)$ showed an increased risk of CLR, it did not reach statistical significance (OR, 10.67; 95\% CI, 0.52 to $217.24 ; \mathrm{p}=0.124)$.

\section{Risk factor for CLR}

The same risk factors as in the multivariable logistic regression analyses affected the quantity of the impedance values $(\Omega)$ in a multiple linear regression analysis (Table 4). In the simple regression analyses, aging reduced the impedance value ( $\beta$ coefficient $=-0.073, \mathrm{p}=0.071$ ), albeit not significantly so. STEMI ( $\beta$ coefficient $=2.317, p=0.030$ ) affected attenuation of the effectiveness of clopidogrel (Table 4). After adjusting for age, sex, use of pantoprazole, existence of PM and history of STEMI, increased age and STMEI were significantly associated with the impedance value in the aggregometer ( $\beta$ coefficient $=-0.086$, $\mathrm{p}=0.024$ and $\beta$ coefficient $=2.625, \mathrm{p}=0.011$ ).

\section{DISCUSSION}

Pantoprazole is a weak inhibitor of CYP2C19, but FDA still releases a precaution about concomitant use of clopidogrel and

Table 3. Risk Factors for Clopidogrel Low-Responders by Univariate and Multivariable Analyses

\begin{tabular}{|c|c|c|c|c|c|c|}
\hline \multirow{2}{*}{ Model variable } & \multicolumn{2}{|l|}{ Univariate } & \multicolumn{4}{|c|}{ Multivariable* } \\
\hline & OR $(95 \% \mathrm{CI})$ & p-value & OR $(95 \% \mathrm{CI})$ & $\mathrm{p}$-value & OR $(95 \% \mathrm{CI})$ & p-value ${ }^{\dagger}$ \\
\hline Age, yr & $0.94(0.85-1.95)$ & 0.261 & $0.79(0.61-1.01)$ & 0.062 & $0.92(0.82-1.03)$ & 0.158 \\
\hline Sex [men] & $3.33(0.26-42.93)$ & 0.356 & & & & \\
\hline Pantoprazole [ranitidine] & $1.06(0.13-8.47)$ & 0.954 & & & & \\
\hline $\mathrm{PM}[\mathrm{EM}]^{\ddagger}$ & $10.67(0.52-217.24)$ & 0.124 & & & & \\
\hline eGFR, $\mathrm{mL} / \mathrm{min}^{\S}$ & $0.95(0.89-1.02)$ & 0.156 & $0.91(0.81-1.02)$ & 0.095 & $1.00(0.99-1.01)$ & 0.483 \\
\hline STEMI [no] & $30.00(2.33-386.33)$ & $0.009^{\prime \prime}$ & $263.03(1.82-38,024.45)$ & $0.028^{\prime \prime}$ & $12.07(0.84-173.78)$ & 0.067 \\
\hline Concentration of clopidogrel & $0.00(0.19-2.94)$ & 0.682 & & & & \\
\hline Concentration of clopidogrel active metabolite & $0.39(0.04-3.74)$ & 0.416 & & & & \\
\hline
\end{tabular}

OR, odds ratio; CI, confidence interval; PM, poor metabolizer; EM, extensive metabolizer; eGFR, estimated glomerular filtration rate; STEMI, STelevation myocardial infarction.

*Adjusted for age, sex, use of pantoprazole, PM, eGFR, STEMI, and concentration of the active clopidogrel metabolite; the reference is described in brackets; ${ }^{\dagger}$ Logistic regression analysis by Firth’s correction; ${ }^{\ddagger} \mathrm{CYP} 2 \mathrm{C} 19$ genotypes were classified into the following three groups: homozygous EM $\left({ }^{*} 1 /{ }^{*} 1\right)$, heterozygous EM $\left(* 1 /{ }^{*} 2\right.$ or $\left.{ }^{*} 1 /{ }^{*} 3\right)$ and PM $\left(* 2 / 2\right.$, ${ }^{*} 3 /{ }^{*} 3$ or $\left.{ }^{*} 2 /{ }^{*} 3\right) ;{ }^{\S}$ eGFR in quartiles using the Cockcroft-Gault formula (corrected for body surface); "Indicates the statistical significance.

Table 4. Linear Association between Proton Pump Inhibitor and Other Risk Factors as Well as Clopidogrel Impedance Values $(\Omega)$

\begin{tabular}{|c|c|c|c|c|c|c|}
\hline \multirow{2}{*}{ Model variable } & \multicolumn{3}{|c|}{ Univariate } & \multicolumn{3}{|c|}{ Multivariable* } \\
\hline & $\beta$ & SE & p-value & $\beta$ & $\mathrm{t}$ & p-value \\
\hline Age, yr & -0.073 & 0.039 & 0.071 & -0.086 & 0.036 & $0.024^{\dagger}$ \\
\hline Sex [men] & 1.242 & 1.285 & 0.340 & & & \\
\hline Pantoprazole [ranitidine] & 1.076 & 0.788 & 0.181 & & & \\
\hline $\mathrm{PM}[\mathrm{EM} \& \mathrm{IM}]^{\ddagger}$ & 2.229 & 1.747 & 0.199 & & & \\
\hline $\mathrm{eGFR}, \mathrm{mL} / \mathrm{min}^{\S}$ & 0.000 & 0.003 & 0.940 & & & \\
\hline STEMI [no] & 2.317 & 1.014 & $0.030^{\dagger}$ & 2.625 & 0.972 & $0.011^{\dagger}$ \\
\hline NSTEMI [no] & -0.070 & 1.097 & 0.950 & & & \\
\hline Concentration of clopidogrel & -0.481 & 0.514 & 0.359 & & & \\
\hline Concentration of clopidogrel active metabolite & -0.257 & 0.167 & 0.143 & & & \\
\hline
\end{tabular}

SE, standard error; PM, poor metabolizer; EM, extensive metabolizer; IM, intermediate metabolizer; eGFR, estimated glomerular filtration rate; STEMI, ST-elevation myocardial infarction; NSTEMI, non-STEMI.

${ }^{*}$ Adjusted for age, sex, use of pantoprazole, PM, and STEMI, and the reference is described in brackets; ${ }^{\dagger}$ Indicates the statistical significance; ${ }^{\ddagger} \mathrm{CYP} 2 \mathrm{C} 19$ genotypes were classified into the following three groups: homozygous EM ( $\left.{ }^{*} 1 /{ }^{*} 1\right)$, heterozygous EM $\left({ }^{*} 1 /{ }^{*} 2\right.$ or $\left.{ }^{*} 1 /{ }^{*} 3\right)$ and PM $\left({ }^{*} 2 /{ }^{*} 2,{ }^{*} 3 /{ }^{*} 3\right.$ or $\left.{ }^{*} 2 /{ }^{*} 3\right)$; ${ }^{8}$ eGFR in quartiles using Cockcroft-Gault formula (corrected for body surface). 
pantoprazole. ${ }^{19}$ The present study showed that pantoprazole does not reduce the antiplatelet effectiveness of clopidogrel. After adjustment for clopidogrel's active metabolite levels and $C Y$ P2C19 genotype, concomitant administration with pantoprazole did not lessen the effect of clopidogrel and no serious bleeding and cardiovascular disease occurred during the study period.

Several mechanisms have been suggested for the drug-drug interactions of PPIs and clopidogrel. One hypothesis is that as the absorption of clopidogrel is enhanced under acidic conditions, the concomitant use of PPIs can reduce drug absorption. ${ }^{20}$ In addition, the competitive inhibition of CYP enzymes between PPIs and clopidogrel was suggested. ${ }^{21}$ It is generally accepted that PPIs have various extents to which their hepatic metabolism depends on a given CYP isoenzyme. ${ }^{22}$ For instance, since pantoprazole has lower affinity for CYP2C19 compared to omeprazole and esomeprazole,,$^{23}$ pantoprazole is expected to have more favorable drug-drug interactions during the secondary biotransformation. ${ }^{24}$

Genetic polymorphisms also naturally influence the CYP2C19 enzymatic activity. CYP2C19 genotypes are generally categorized into homo EM, hetero EM and PM by analysis of the most common loss-of function alleles, CYP2C19*2 in exon 5 and CYP2C19*3 in exon 4. ${ }^{7,25}$ Hence, differences in CYP2C19 polymorphisms may result in different metabolism of clopidogrel with variable risk for cardiovascular events. There are also racial variance in the distribution of this genetic polymorphisms. ${ }^{25}$ The prevalence of homo EM in Caucasians has been reported to be $72.6 \%$, ${ }^{26}$ which is greater than the $41.3 \%$ reported in Koreans. ${ }^{27}$

To address the effect of heterogeneity of CYP2C19 genotypes on drug-drug interaction between pantoprazole and clopidogrel in Korea, the concentration of clopidogrel and the active metabolites of clopidogrel and the CYP2C19 genotypes were evaluated in the present study. After adjusting for the active metabolites of clopidogrel and the CYP2C19 genotypes, our study provided additional evidence that the concomitant use of pantoprazole does not impede the antiplatelet effectiveness of clopidogrel and the concentration of its active metabolite. This was consistent with the TRITON-TIMI 38 trial, which found that a reduced-function CYP2C19 allele was not related with an elevated risk of adverse cardiovascular events in patients treated with prasugrel. ${ }^{28}$ Although the debate continues regarding the interactions between clopidogrel and PPIs, ${ }^{29}$ growing number of studies failed to show that clopidogrel in association with PPIs reduce the activity of clopidogrel. ${ }^{30,31}$ After administration of ranitidine or pantoprazole in the present study, CLR occurred in about $10 \%$ in both medicines. Though the statistics for the concentration of clopidogrel and its metabolites were not different before and after the administration of pantoprazole and ranitidine, the development of CLR may seem significant. Actually, the prevalence of clopidogrel resistance is highly variable in different studies and populations. A review ${ }^{10}$ estimated the nonresponse rate to range from $4 \%$ to $30 \%$. This variability is partly caused by the lack of standard definition and the different assessment methods of clopidogrel nonresponse. ${ }^{32}$ Furtado et $a l^{33}$ who reported approximately $10 \%$ of difference between the two treatment groups, also evaluated platelet function using VerifyNow P2Y12TM for Brazilians. Therefore, there is a possibility that direct comparison between studies without unification of race and assessment methods would be insignificant.

One of the limitations in our analysis is a small sample size. The pantoprazole group or PM group might have been too small to show any association between PPI use and the risk of pharmacodynamics outcomes, if such a relationship in fact existed. We provided ranitidine to the control group instead of comparing two groups with or without pantoprazole, since most of participants have epigastric pain which is related with administration of antiplatelet agents. It has been recognized that ranitidine did not influence the clopidogrel antiplatelet activity. ${ }^{34,35}$ Additional limitation to the present study is the application of only one method of defining CLR. An important reason for inconsistent results regarding the potential effect of PPI on clopidogrel is differences in the methodologies used for detection and definitions of "platelet resistance." ${ }^{36}$ One patient who showed posttreatment clopidogrel reactivity in the ranitidine group might be result from other genetic and nongenetic factors which influence pharmacokinetics/pharmacodynamics of clopidogrel. ${ }^{37}$ They might be initially resistant to clopidogrel if multiple methods would be used to determine CLR.

Nonetheless, this was a rare randomized controlled study which at least confirmed drug compliance by measuring the concentration of clopidogrel and the active metabolite in blood. While most studies about the present topic were conducted in Western countries, we performed multivariable adjustments for potential confounders, including CYP2C19 genotypes for Koreans.

Prescription of PPIs is increasing because it has been recommended not for the prevention of GI bleeding but for the treatment of gastroesophageal reflux disease. ${ }^{38,39}$ According to the increased incidence of cardiovascular and cerebrovascular diseases, more frequent concomitant use of clopidogrel and PPIs is expected. Based on our study, using pantoprazole for patients on dual antiplatelet therapy with an indication for PPI medication could be safe.

\section{CONFLICTS OF INTEREST}

No potential conflict of interest relevant to this article was reported.

\section{ACKNOWLEDGEMENTS}

This work was supported by grant number 06-2011-186 from the Seoul National University Bundang Hospital Research.

We thank Mr. Min Chang Kim and Ms. Hyesoo Lee for quan- 
tifying pantoprazole, clopidogrel and clopidogrel metabolites. The authors are indebted to the Division of Statistics in Medical Research Collaborating Center at Seoul National University Bundang Hospital for statistical analyses.

Author contributions: Y.J.C. analyzed data and drafted the article; N.K. designed this study, collected the data and supervised the writing of the manuscript; I.J.J. and J.Y.C. measured the concentrations of clopidogrel and its metabolite; R.H.N. collected the data and specimens. J.H.P. performed CYP genotyping; H.J.J. helped the design of this study and Y.S.P. contributed to the enrollment of the patients; H.Y. and C.M.S. provided statistical support and edited the manuscript; D.H.L. and H.C.J. provided advice on the study design and supervised the writing of the manuscript. All authors have read and approved the final draft of this paper.

\section{REFERENCES}

1. Choi CK, Kim N, Choi JW, et al. Effect of low-dose, enteric coated aspirin on gastrointestinal bleeding in patients with coronary artery disease. Gut Liver 2008;2:99-104.

2. Bhatt DL, Scheiman J, Abraham NS, et al. ACCF/ACG/AHA 2008 expert consensus document on reducing the gastrointestinal risks of antiplatelet therapy and NSAID use: a report of the American College of Cardiology Foundation Task Force on Clinical Expert Consensus Documents. J Am Coll Cardiol 2008;52:1502-1517.

3. Laine L. Review article: gastrointestinal bleeding with low-dose aspirin: what's the risk? Aliment Pharmacol Ther 2006;24:897908.

4. Derry S, Loke YK. Risk of gastrointestinal haemorrhage with long term use of aspirin: meta-analysis. BMJ 2000;321:1183-1187.

5. Yusuf S, Zhao F, Mehta SR, et al. Effects of clopidogrel in addition to aspirin in patients with acute coronary syndromes without STsegment elevation. N Engl J Med 2001;345:494-502.

6. Ng FH, Lam KF, Wong SY, et al. Upper gastrointestinal bleeding in patients with aspirin and clopidogrel co-therapy. Digestion 2008;77:173-177.

7. Goh KL, Choi MG, Hsu PI, et al. Pharmacological and safety profile of dexlansoprazole: a new proton pump inhibitor: implications for treatment of gastroesophageal reflux disease in the Asia Pacific region. J Neurogastroenterol Motil 2016;22:355-366.

8. Furuta T, Shirai N, Sugimoto M, Nakamura A, Hishida A, Ishizaki T. Influence of CYP2C19 pharmacogenetic polymorphism on proton pump inhibitor-based therapies. Drug Metab Pharmacokinet 2005;20:153-167.

9. Shin JM, Kim N. Pharmacokinetics and pharmacodynamics of the proton pump inhibitors. J Neurogastroenterol Motil 2013;19:2535.

10. Gilard M, Arnaud B, Cornily JC, et al. Influence of omeprazole on the antiplatelet action of clopidogrel associated with aspirin: the randomized, double-blind OCLA (Omeprazole CLopidogrel Aspirin) study. J Am Coll Cardiol 2008;51:256-260.
11. Juurlink DN, Gomes T, Ko DT, et al. A population-based study of the drug interaction between proton pump inhibitors and clopidogrel. CMAJ 2009;180:713-718.

12. Lee JY, Kim N, Kim GH, Kim GH. Comparing the areas of interest in the field of functional gastrointestinal disorder and neurogastroenterology and motility between the East and the West. J Neurogastroenterol Motil 2015;21:503-510.

13. U.S. Food and Drug Administration. Drug safety labeling changes [Internet]. Silver Spring: U.S. Food and Drug Administration; c2012 [cited 2016 Jun 30]. Available from: http://www.fda.gov/ Safety/MedWatch/SafetyInformation/ucm284231.htm.

14. Neubauer H, Lask S, Engelhardt A, Mügge A. How to optimise clopidogrel therapy? Reducing the low-response incidence by aggregometry-guided therapy modification. Thromb Haemost 2008;99:357-362.

15. Ivandic BT, Schlick P, Staritz P, Kurz K, Katus HA, Giannitsis E. Determination of clopidogrel resistance by whole blood platelet aggregometry and inhibitors of the P2Y12 receptor. Clin Chem 2006;52:383-388.

16. Herbert JM, Frehel D, Vallee E, et al. Clopidogrel, a novel antiplatelet and antithrombotic agent. Cardiovascul Drugs Rev 1993;11:180-198.

17. de Morais SM, Wilkinson GR, Blaisdell J, Nakamura K, Meyer UA, Goldstein JA. The major genetic defect responsible for the polymorphism of S-mephenytoin metabolism in humans. J Biol Chem 1994;269:15419-15422.

18. Choi KD, Kim N, Jang IJ, et al. Optimal dose of intravenous pantoprazole in patients with peptic ulcer bleeding requiring endoscopic hemostasis in Korea. J Gastroenterol Hepatol 2009;24:1617-1624.

19. U.S. Food and Drug Administration. Drug safety labeling changes [Internet]. Silver Spring: U.S. Food and Drug Administration; c2011 [cited 2016 Jun 30]. Available from: http://www.fda.gov/ Safety/MedWatch/SafetyInformation/ucm280101.htm.

20. Neubauer H, Engelhardt A, Krüger JC, et al. Pantoprazole does not influence the antiplatelet effect of clopidogrel: a whole blood aggregometry study after coronary stenting. J Cardiovasc Pharmacol 2010;56:91-97.

21. Andersson T, Hassan-Alin M, Hasselgren G, Röhss K. Drug interaction studies with esomeprazole, the (S)-isomer of omeprazole. Clin Pharmacokinet 2001;40:523-537.

22. Humphries TJ, Merritt GJ. Review article: drug interactions with agents used to treat acid-related diseases. Aliment Pharmacol Ther 1999;13 Suppl 3:18-26.

23. Radhofer-Welte S. Pharmacokinetics and metabolism of the proton pump inhibitor pantoprazole in man. Drugs Today (Barc) 1999;35:765-772.

24. Cheer SM, Prakash A, Faulds D, Lamb HM. Pantoprazole: an update of its pharmacological properties and therapeutic use in the management of acid-related disorders. Drugs 2003;63:101-133.

25. De Morais SM, Wilkinson GR, Blaisdell J, Meyer UA, Nakamura K, Goldstein JA. Identification of a new genetic defect responsible for the polymorphism of (S)-mephenytoin metabolism in Japanese. 
Mol Pharmacol 1994;46:594-598.

26. Lim PW, Goh KL, Wong BC. CYP2C19 genotype and the PPIs: focus on rabeprazole. J Gastroenterol Hepatol 2005;20 Suppl:S22S28.

27. Kang JM, Kim N, Lee DH, et al. Effect of the CYP2C19 polymorphism on the eradication rate of Helicobacter pylori infection by 7-day triple therapy with regular proton pump inhibitor dosage. J Gastroenterol Hepatol 2008;23(8 Pt 1):1287-1291.

28. Mega JL, Close SL, Wiviott SD, et al. Cytochrome P450 genetic polymorphisms and the response to prasugrel: relationship to pharmacokinetic, pharmacodynamic, and clinical outcomes. Circulation 2009;119:2553-2560.

29. Rassen JA, Choudhry NK, Avorn J, Schneeweiss S. Cardiovascular outcomes and mortality in patients using clopidogrel with proton pump inhibitors after percutaneous coronary intervention or acute coronary syndrome. Circulation 2009;120:2322-2329.

30. O'Donoghue ML, Braunwald E, Antman EM, et al. Pharmacodynamic effect and clinical efficacy of clopidogrel and prasugrel with or without a proton-pump inhibitor: an analysis of two randomised trials. Lancet 2009;374:989-997.

31. Bhatt DL, Cryer BL, Contant CF, et al. Clopidogrel with or without omeprazole in coronary artery disease. N Engl J Med 2010;363:1909-1917.

32. Nguyen TA, Diodati JG, Pharand C. Resistance to clopidogrel: a review of the evidence. J Am Coll Cardiol 2005;45:1157-1164.
33. Furtado RH, Giugliano RP, Strunz CM, et al. Drug Interaction between clopidogrel and ranitidine or omeprazole in stable coronary artery disease: a double-blind, double dummy, randomized study. Am J Cardiovasc Drugs 2016;16:275-284.

34. Furtado R, Freire BT, Strunz C, et al. Drug interaction between clopidogrel and ranitidine or omeprazole in patients with coronary heart disease: a double-blind, double-dummy, randomized comparative study. J Am Coll Cardiol 2014;63:A1521.

35. Small DS, Farid NA, Li YG, et al. Effect of ranitidine on the pharmacokinetics and pharmacodynamics of prasugrel and clopidogrel. Curr Med Res Opin 2008;24:2251-2257.

36. Bonello L, Tantry US, Marcucci R, et al. Consensus and future directions on the definition of high on-treatment platelet reactivity to adenosine diphosphate. J Am Coll Cardiol 2010;56:919-933.

37. Jiang XL, Samant S, Lesko LJ, Schmidt S. Clinical pharmacokinetics and pharmacodynamics of clopidogrel. Clin Pharmacokinet 2015;54:147-166.

38. Kim SE, Kim N, Oh S, et al. Predictive factors of response to proton pump inhibitors in kKorean patients with gastroesophageal reflux disease. J Neurogastroenterol Motil 2015;21:69-77.

39. Min YW, Shin YW, Cheon GJ, et al. Recurrence and its impact on the health-related quality of life in patients with gastroesophageal reflux disease: a prospective follow-up analysis. J Neurogastroenterol Motil 2016;22:86-93. 